\title{
A DIFERENCIAÇÃo DE PREÇOS CONFORME OS MEIOS DE PAGAMENTO E SEUS IMPACTOS PARA O CONSUMIDOR
}

\author{
Daniela Silva Fontoura de Barcellos ${ }^{1}$ \\ Tatiana Silva Fontoura de Barcellos Giacobbo ${ }^{2}$
}

\section{Resumo}

Esse artigo tem como objetivo verificar o impacto para o consumidor da Lei 13.455/2017, de diferenciação de preços, utilizando como metodologia a análise econômica do direito e tendo como referência temporal o novo marco legal. Assim, na primeira parte, compara-se o entendimento predominante anterior, com a nova legislação que pacificou a possibilidade de diferenciação de preços, zerando as demandas judiciais. A segunda parte trata da vulnerabilidade econômica do consumidor considerado como indivíduo e como grupo, destacando-se que apesar da ausência de consulta dos órgãos defesa do consumidor - majoritariamente autodeclarados contrários à mudança - a medida foi especialmente benéfica para a população de baixa renda. Por fim, descreve os meios de pagamentos no Brasil e se realiza uma análise inédita das evidências empíricas sobre o mercado de crédito, a partir de dados do Banco Central, demonstrando, conclusivamente, que tal medida não alterou substancialmente o comportamento econômico dos consumidores de classe média e alta, que continuam a realizar compras no cartão de crédito e a usufruir dos parcelamentos sem juros e de benefícios indiretos como os oferecidos tais como programas de milhagens e promoções.

Palavras-chave: Diferenciação de preços. Análise econômica do Direito. Direito do Consumidor. Grupos Vulneráveis. Vulnerabilidade Econômica.

\section{INTRODUÇÃO}

Este artigo tem como objetivo verificar o impacto para o consumidor da diferenciação de preços, tendo em vista os meios de pagamento - dinheiro, cheque, débito ou crédito. Esta permissão, trazida pela Medida Provisória 764, de 26 de dezembro de 2016, foi posteriormente convertida na Lei 13.455 , de 26 de junho de 2017 e atualmente está em vigor no país. Importante ressaltar que a lei dispõe sobre a possibilidade de diferenciação de preços tendo em vista não apenas meios de

\footnotetext{
1 Professora adjunta da Faculdade Nacional de Direito e do PPGD da UFRJ. Doutora em Ciência Política pela Universidade Federal do Rio Grande do Sul (UFRGS), com estágio doutoral na Ecole Normale Supérieure e Université de Paris I, Panthéon Sorbonne. Mestre em Direito Civil e do Consumidor na UFRGS. Instituição: Universidade Federal do Rio de Janeiro - UFRJ, Rio de Janeiro. Brasil. E-mail: barcellosdanielasf@gmail.com

2 Doutoranda em Economia Unisinos; Mestre em Economia pela UFRGS. Instituição: Universidade do Vale do Rio dos Sinos - Unisinos, Rio Grande do Sul. Brasil. E-mail: tatianasfbarcellos@gmail.com
} 
pagamento, mas também prazos. No entanto, por ser este último aspecto uma prática já consolidada e corroborada por outras leis e normas infralegais (Vg. Resolução do BACEN 3.517/2007) não será objeto deste estudo.

A diferenciação de preços em função dos meios de pagamento já ocorria no mercado informalmente e favorece, a princípio, aqueles consumidores que pagam em dinheiro à vista. No entanto, antes da Lei 13.455/17, o entendimento jurídico predominante era que independentemente do meio de pagamento - dinheiro, cheque, débito ou crédito - o preço dos produtos e serviços deveria ser o mesmo. Com a mudança, o consumidor perde esta certeza do preço fixo em nome de uma possível diminuição de preços a depender do meio de pagamento realizado.

Tendo como ponto de partida uma rápida pesquisa na imprensa, percebe-se que nem os agentes do Estado competentes para a matéria - Banco Central do Brasil e Ministério da Economia, de um lado, e Senacon e Procons, de outro - convergem sobre o entendimento do tema. Capitaneada pelo Banco Central do Brasil, a diferenciação de preços foi justificada pelo então Ministro da Economia, Henrique Meirelles, por "eliminar o subsidio cruzado, aumentar a eficiência econômica e tornar o ambiente regulatório mais transparente e competitivo" (CORRÊA, 2018). Já as entidades de defesa do consumidor, que não foram chamadas a opinar na elaboração desta lei, manifestam-se contrárias, por entenderem que "a medida pode, na verdade, ocasionar uma majoração dos preços de produtos e serviços quando o consumidor preferir pagar com cartão" (PROCON-SP, 2017).

Diante deste cenário, o presente artigo tem por objetivo analisar os impactos da Lei 13.455/2017 para o consumidor no cenário econômico brasileiro. O objetivo do trabalho é verificar se a lei de diferenciação de preços é benéfica ou não ao consumidor final, sob os aspectos legais e econômicos. A hipótese principal é de que essa autorização legal de diferenciação de preços é benéfica para a economia, uma vez que permite ao consumidor pagar menos, caso opte pelo pagamento à vista, eliminando os custos da intermediação financeira a crédito. Para a verificação da hipótese, utiliza-se como metodologia a análise econômica do direito (COOTER \& ULEN, 2010), empregando instrumentais teóricos e empíricos econômicos para a avaliação dos impactos desta lei em comparação ao cenário legal até então vigente.

Assim, na primeira parte, apresenta-se o marco legal do tema, comparando o entendimento predominante anterior, que era pela impossibilidade de diferenciação de preços, com a nova legislação. A segunda parte trata da vulnerabilidade econômica do consumidor, considerado como indivíduo e como grupo. Por fim, a terceira parte do trabalho descreve os meios de pagamentos no Brasil e realiza uma análise inédita das evidências empíricas sobre o mercado de crédito, a partir de dados do Banco Central do Brasil. 


\section{DA PROIBIÇÃO À PERMISSÃO: DIFERENCIAÇÃO DE PREÇOS E SEU MARCO LEGAL}

No que diz respeito à possibilidade de diferenciação de preços tendo em vista meios de pagamento, tivemos na história recente do país dois entendimentos diferentes: a proibição e a permissão. De fato, até o ano de 2016, tal prática era vedada. A regulamentação da proibição da diferenciação de preços se deu primeiramente, mediante cláusulas gerais do Código de Proteção e Defesa do Consumidor e, num segundo momento, pela Lei 12.529, de 30 de novembro de 2011, com regras bastante detalhadas.

A partir de dezembro de 2016 houve alteração legislativa permitindo a diferenciação de preços de produtos e serviços oferecidos ao público, em função do prazo ou do instrumento de pagamento utilizado. Esta mudança ocorreu, inicialmente, pela promulgação da Medida Provisória 764/2016, e, em seguida, foi convertida na Lei 13.455, de 26 de junho de 2017.

Sendo assim, neste capítulo aborda-se o marco legal da regulação da diferenciação de preços no Brasil, dividindo o capítulo em duas partes. A primeira se ocupará do período em que a diferenciação de preços era proibida e a segunda, do momento presente, em que a mesma é possível.

\subsection{O Código de Defesa do Consumidor e a proibição da diferenciação de preços}

Até o advento da alteração legislativa realizada pela Medida Provisória 764 em 2016, predominava no direito brasileiro o entendimento pela proibição da diferenciação de preços dos produtos e serviços tendo em vista os meios de pagamento. $\mathrm{O}$ fundamento legal para coibir tal prática fundamentava-se, inicialmente, no Código de Defesa do Consumidor, interpretando-se dentre os incisos do rol de práticas abusivas do art. 39, o inciso X, que proíbe explicitamente a elevação "sem justa causa o preço de produtos ou serviços". Com frequência de forma alternada ou cumulada, ao lado do art. 39, X a diferenciação de preços também era considerada, nos termos do inciso V do mesmo art. 39 do CDC como "vantagem manifestamente excessiva".

Caso esta prática estivesse explicitada em contrato escrito, era vista como cláusula abusiva sendo sua proibição coibida pelo art. 51, IV, do CDC, que considera nula de pleno direito a cláusula que "estabeleçam obrigações consideradas iníquas, abusivas, que coloquem o consumidor em 
desvantagem exagerada, ou sejam incompativeis com a boa-fé ou a equidade”. Sendo assim, desde 1991, ano de entrada em vigor do Código de Proteção e Defesa do Consumidor, a alteração de preços em função do meio de pagamento - dinheiro, cheque, débito ou crédito - era predominantemente considerada proibida seja por ser considerada prática abusiva (art. 39, V e X, do CDC) seja por ser cláusula abusiva (art. 51, IV, do CDC).

Segue, abaixo, um acórdão demonstrativo desta compreensão, que proíbe preços diferenciados para a venda de combustível em dinheiro, cheque e cartão de crédito.

Recurso Especial. Ação coletiva de consumo. Cobrança de preços diferenciados para venda de combustível em dinheiro, cheque e cartão de crédito. Prática de consumo abusiva. Verificação. Recurso especial provido. I - Não se deve olvidar que o pagamento por meio de cartão de crédito garante ao estabelecimento comercial o efetivo adimplemento, já que, como visto, a administradora do cartão se responsabiliza integralmente pela compra do consumidor, assumindo o risco de crédito, bem como de eventual fraude; II - O consumidor, ao efetuar o pagamento por meio de cartão de crédito (que só se dará a partir da autorização da emissora), exonera-se, de imediato, de qualquer obrigação ou vinculação perante o fornecedor, que deverá conferir àquele plena quitação. Está-se, portanto, diante de uma forma de pagamento à vista e, ainda, pro soluto" (que enseja a imediata extinção da obrigação); III - O custo pela disponibilização de pagamento por meio do cartão de crédito é inerente à própria atividade econômica desenvolvida pelo empresário, destinada à obtenção de lucro, em nada referindose ao preço de venda do produto final. Imputar mais este custo ao consumidor equivaleria a atribuir a este a divisão de gastos advindos do próprio risco do negócio (de responsabilidade exclusiva do empresário), o que, além de refugir da razoabilidade, destoa dos ditames legais, em especial do sistema protecionista do consumidor; IV - O consumidor, pela utilização do cartão de crédito, já paga à administradora e emissora do cartão de crédito taxa por este serviço (taxa de administração). Atribuir-lhe ainda o custo pela disponibilização de pagamento por meio de cartão de crédito, responsabilidade exclusiva do empresário, importa em onerá-lo duplamente (in bis idem) e, por isso, em prática de consumo que se revela abusiva; V - Recurso Especial provido. [REsp 1133410/RS, 3 T. Rel. Min. Massami Uyeda, j. em 16/03/2010, DJe 07/04/2010]

No entanto, neste período, por não haver a proibição explícita a prática de diferenciação de preços, as próprias turmas STJ divergiam entre si, havendo aquelas que entendiam que a mesma era permitida.

(...) 2. A orientação das Turmas que integram a Primeira Seção desta Corte, firmou-se no sentido de que a simples oferta de desconto nas vendas feitas com dinheiro ou cheque, em relação às efetuadas por meio de cartão de crédito, não encontra óbice legal, pela inexistência de lei que proíba essa diferenciação, e por não caracterizar abuso de poder econômico. Agravo regimental improvido. [STJ..AgRg no REsp 1178360/SP, $2^{\text {a }}$ T Rel. Min. Humberto Martins, j. em 05/08/2010, DJe 19/08/2010] 
Em 2011, além do CDC, o ordenamento jurídico brasileiro passou a contar com a Lei 12.529, de 30 de novembro de 2011, que estrutura a defesa da concorrência. Esta reconhece explicitamente como infração à ordem econômica a diferenciação de preços em seu art. 36, incisos $\mathrm{X}$ e XI, in verbis:

$\mathrm{X}$ - discriminar adquirentes ou fornecedores de bens ou serviços por meio da fixação diferenciada de preços, ou de condições operacionais de venda ou prestação de serviços;

XI - recusar a venda de bens ou a prestação de serviços, dentro das condições de pagamento normais aos usos e costumes comerciais;

Sendo assim, o entendimento predominante de proibição de diferenciação de preços, em função do meio de pagamento, com base na interpretação dos arts. 39 e 51 do CDC, ganhou força com o auxílio da norma explícita do art. 36, X e XI da Lei 12.529/11.

O controle desta proibição poderia ser feita tanto judicialmente, como por via administrativa, no CADE ou nos PROCONs (e, anteriormente, mediante atuação da SUNAB). Tendo em vista a atuação dos PROCONs estaduais ou municipais, no combate à diferenciação de preços, diversas entidades varejistas ingressaram em juízo tentando afastar a decisão administrativa dos órgãos de defesa do consumidor. No entanto, estas tentativas não obtiveram êxito e as multas e demais penalidades administrativas impostas costumavam ser mantidas pelo Poder Judiciário.

(...) 5. A diferenciação entre o pagamento em dinheiro, cheque ou cartão de crédito caracteriza prática abusiva no mercado de consumo, nociva ao equilíbrio contratual. Exegese do art. 39, V e X, do CDC: (...) 6. O art. 51 do CDC traz um rol meramente exemplificativo de cláusulas abusivas, num "conceito aberto" que permite o enquadramento de outras abusividades que atentem contra o equilíbrio entre as partes no contrato de consumo, de modo a preservar a boa-fé e a proteção do consumidor. 7. A Lei n. 12.529/2011, que reformula o Sistema Brasileiro de Defesa da Concorrência, considera infração à ordem econômica, a despeito da existência de culpa ou de ocorrência de efeitos nocivos, a discriminação de adquirentes ou fornecedores de bens ou serviços mediante imposição diferenciada de preços, bem como a recusa à venda de bens ou à prestação de serviços em condições de pagamento corriqueiras na prática comercial (art. 36, X e XI).Recurso especial da Câmara de Dirigentes Lojistas de Belo Horizonte conhecido e improvido. [STJ. $2^{\text {a }}$ T. REsp 1479039/MG, Rel. Min. Humberto Martins, j. em 06/10/2015]

Em 11 de outubro de 2014, adveio a Lei 10.962, que dispõe sobre a oferta e a forma de fixação de preços de produtos e serviços ao consumidor. O foco desta lei era sobretudo a preservação do direito à informação do consumidor sobre o preço à vista, tendo em vista também as novas técnicas de afixação de preços, como os códigos de barras nas gôndolas de vendas. No 
entanto, não dispôs inicialmente sobre a possibilidade de diferenciação de preços, mas apenas determinou a obrigatoriedade de afixação do preço à vista (art. 2º, I, da Lei 10.962/14).

\subsection{A permissão de diferenciação de preços a partir da MP 764/16}

A inserção da variação de preços tendo em vista o prazo ou a forma de pagamentos foi realizada pela Medida Provisória 764/2016, em seguida convertida na Lei 13.455/17.

Para sua realização foi criado um Grupo de Trabalho do Banco Central, juntamente com a ANATEL e o Ministério das Comunicações ${ }^{3}$. Em paralelo, o Congresso Nacional realizou em seu site uma consulta pública para saber a opinião popular a respeito da implementação desta medida, tendo obtido a predominância de votos favoráveis, apesar da baixa participação popular. No total foram 170 votos favoráveis e 135 votos contrários. (CONGRESSO NACIONAL, 2018). Já a Secretaria Nacional do Consumidor do Ministério da Justiça - Senacon - não foi chamada a participar.

Assim, repetindo o disposto na MP 764/16 a Lei 13.455/17 em seu art. $1^{\circ}$ determina que "fica autorizada a diferenciação de preços de bens e serviços oferecidos ao público em função do prazo ou do instrumento de pagamento utilizado". Além disso, proíbe o afastamento de tal liberdade por cláusula contratual, trazendo como penalidade a nulidade de tal disposição contratual (vide parágrafo único do art. $1^{\circ}$ da Lei $\left.13.455 / 17\right)$.

A única ressalva feita pela Lei 13.455/17. em seu art. 12, é a necessidade de informar o consumidor de forma adequada - em local e formato visíveis - os eventuais descontos oferecidos em função do prazo ou do instrumento de pagamento utilizado.

Ademais, a Lei 13.455/17 inclui na Lei 10.962/14 o direito ao consumidor de ser informado adequadamente a respeito do preço do produto ou serviço, tendo em vista o prazo ou os meios de pagamento. Assim dispõe o art. $5^{\circ}$-A da Lei 10.962/14 com redação dada pela Lei 13.455/17: " $O$ fornecedor deve informar, em local e formato visiveis ao consumidor, eventuais descontos oferecidos em função do prazo ou do instrumento de pagamento utilizado."

A partir da entrada em vigor da nova lei, inúmeras entidades de defesa do consumidor, sobretudo PROCONs (PROCON-SP, 2017) as organizações não governamentais de defesa do consumidor (PROTESTE, 2018), manifestaram-se contrárias à nova lei. Por outro lado, as entidades econômicas estatais, os economistas e parte dos juristas (BESSA et al., 2017) manifestam-se favoráveis à medida.

O que não foi levantado ainda nas primeiras opiniões sobre o tema é a segurança jurídica. Após a lei, não foram encontradas mais a ações judiciais sobre a impossibilidade de diferenciação de preços. A seguir, faz-se uma análise do tema, tendo em vista a chamada vulnerabilidade do consumidor.

\section{GRUPOS VULNERÁVEIS E A DIFERENCIAÇÃO DE PREÇOS TENDO EM VISTA OS MEIOS DE PAGAMENTO}

\footnotetext{
${ }^{3}$ Esta ação está em consonância com as iniciativas do Banco Central do Brasil para promoção da Inclusão Financeira (vide Banco Central do Brasil, 2014.)
} 
O direito do consumidor, em sua lei fundante no Brasil, a Lei 8.078/90, o Código de Defesa do Consumidor, trouxe um novo específico para a vulnerabilidade. Mas ao lado desta significação, existe outra, a de grupos vulneráveis, que, ao ter como o critério o econômico, divide os consumidores em faixas de renda. Sendo assim, faremos uma breve exposição do conceito de vulnerabilidade na lei consumerista, e em seguida, uma análise da inserção de parte dos consumidores como grupo economicamente vulnerável. Tal distinção se faz relevante, pois a vulnerabilidade econômica do consumidor, pode permitir a políticas direcionadas a determinadas faixas de renda.

\subsection{A vulnerabilidade econômica do consumidor}

No Código de Defesa do Consumidor, a vulnerabilidade aparece como elemento caracterizador do conceito de consumidor (integrando implicitamente o conceito do art. $2^{\circ}$, caput, do CDC) e como princípio (art. $4^{\circ}, \mathrm{I}$, do CDC). Vista como princípio, a vulnerabilidade rege a interpretação das cláusulas contratuais e das normas de consumo direcionando-as em favor da parte mais fraca. Como integrante do conceito de consumidor, ela dá direito à proteção especial do Código consumerista.

A fim de tornar mais fácil a concretização da vulnerabilidade, a doutrina se ocupou em tipificar suas espécies. Havendo a presença de uma delas, em maior ou menor grau, o consumidor terá a presunção de sujeito mais fraco na relação jurídica com o fornecedor. Cláudia Lima Marques formulou inicialmente uma divisão em três tipos: técnica, jurídica e fática (MARQUES, 2014). Em seguida, outras formulações foram feitas, tal como a de Paulo Valério Moraes (2009, p. 115), que por sua vez, identificou seis espécies de vulnerabilidade: técnica, jurídica, ambiental, econômica, político-legislativa e psíquica.

Neste trabalho, parte-se da caracterização de Moraes (2009), para construir uma posição intermediária, excluindo as vulnerabilidades ambiental e político-legislativa. Isto porque embora sejam duas espécies de vulnerabilidade relevantes na sociedade de consumo, elas não têm o condão de caracterizar o consumidor, pois também são inerentes a outros segmentos sociais (BARCELLOS, 2007). 
A vulnerabilidade técnica manifesta-se pela ausência de conhecimentos específicos em relação ao produto ou ao serviço, tornando-o suscetível de ser enganado ou prejudicado. A vulnerabilidade jurídica é falta de conhecimentos quanto a direitos, instrumentos contratuais e remédios jurídicos para solucionar eventuais problemas. A vulnerabilidade psíquica manifesta-se pelo uso das mais diversas técnicas de venda que induzem o consumidor a comprar o que não precisa, não quer, e muitas vezes, também o que não pode pagar.

Por fim, a vulnerabilidade econômica provoca um desequilíbrio na negociação, pois o consumidor possui poder de barganha inversamente proporcional a seu poder de compra. Desta vulnerabilidade, decorre o princípio "poor pays more" do direito americano, ou seja, o pobre paga mais.

Além da vulnerabilidade, há outra manifestação da weak-position reconhecida no Código do Consumidor: a cláusula geral da hipossuficiência. Esta é um dos critérios de concessão do benefício da inversão ônus da prova no processo civil (art. $6^{\circ}$, VIII, do CDC). Usualmente, tem-se que a mesma é reconhecida sempre que o fornecedor tiver os meios de prova em sua posse ou quando a prova necessitar de conhecimento técnico disponível ao fornecedor.

Sendo assim, em síntese na sua formulação no âmbito do direito do consumidor a vulnerabilidade apresenta-se com duplo viés: princípio fundante do direito do consumidor (art. $4^{\circ}$, III, do CDC) e qualidade essencial do conceito de consumidor (BARCELLOS, 2007). Na esfera processual, a vulnerabilidade ganha a denominação de "hipossuficiência" e traz como consequência a possibilidade de inversão do ônus da prova.

Atualmente, após quase 30 anos de vigência do CDC, a noção de vulnerabilidade nas relações de consumo ganhou novos desdobramentos e passou a ser tratada, em determinadas situações, como "hipervulnerabilidade". Este conceito também denominado vulnerabilidade agravada surge no Superior Tribunal de Justiça, em um julgado que reconhece direito à informação aos consumidores celíacos para além da chamada Lei do Glúten. Neste importante acórdão, o Ministro Antônio Herman Benjamin atribui ao Estado Social a preocupação:

não apenas o vulneráveis, mas sobretudo os hipervulneráveis, pois são estes que, exatamente por serem minoritários e amiúde discriminados ou ignorados, mas sofrem com a massificação do consumo e a pasteurização das diferenças que caracterizam e enriquecem a sociedade moderna. [STJ. $2^{\mathrm{a}}$ T. REsp 586.316/MG, Rel. Min. Herman Benjamin, j. em 17/04/2007]

A partir daí, desenvolveu-se uma ampla gama de estudos sobre os "novos" consumidores, cuja proteção mais atenta já estava prevista desde a criação da lei 8.0780/90, embora não unificados legislativamente sob a categoria de hipervulneráveis. 


\subsection{A diferenciação de preços e os grupos economicamente vulneráveis}

$\mathrm{Na}$ literatura consumerista há um consenso de que não há "consumidor médio", pois a singularidade de cada um não é passível de ser contemplada grupos (BOURGOIGNIE, 1992). No entanto, quando se trata da vulnerabilidade econômica do consumidor, não há empecilho de se fazer uma análise por grupos tendo em vista o poder aquisitivo.

Sendo assim, partiu-se do fato de que mais de $60 \%$ dos consumidores brasileiros não utilizam cartão de crédito (BACEN:2018). Além disso, podemos diferenciar os usuários de cartão de crédito em dois grupos: os consumidores que pagam anuidade de cartão e, muitas vezes, entram no rotativo e os que, por estarem em uma faixa superior de renda, não pagam anuidades e são usuários de benefícios oriundo dos cartões, especialmente os programas de milhagem.

Diferentemente da expressão "minoria", que remete a um grupo numericamente menor, "grupo vulnerável” designa um contingente destituídos de poder na sociedade, independentemente de serem ou não uma maioria numérica (GUERRA e EMERIQUE, 2008, p. 16). Por isso, enquadram-se nesta designação, dentre outros, as pessoas de baixa renda.

Sendo assim, cabe ressaltar que, de acordo com o BACEN $60 \%$ dos consumidores brasileiros não faz uso de cartão de crédito. Sendo os preços calculados com as custas das taxas cobradas pelas operadoras de cartões de crédito aos comerciantes, e não havendo diferenciação de preços por meios de pagamento, os consumidores mais pobres estão subsidiando o consumo dos consumidores mais ricos, que pagam suas compras com cartão. É o chamado subsídio cruzado, assim denominado pelos economistas, tal como na declaração de Meirelles por ocasião da promulgação da nova lei (in: CORRÊA, 2018)

Assim, antes de expressar opiniões apressadas, ainda que cheias de "boas intenções" no que diz respeito à defesa do consumidor, fundamental se faz uma análise da situação fática de acordo com os instrumentos da análise econômica do direito, a fim de se construir uma opinião fundamentada no conhecimento concreto da situação no país, o que será feito a seguir.

\section{MEIOS DE PAGAMENTOS E AS EVIDÊNCIAS DOS IMPACTOS DA DIFERENCIAÇÃO DE PREÇOS PARA O ACESSO AO CONSUMO NO BRASIL}


Para uma conclusão sobre os primeiros impactos da diferenciação de preços para o consumidor, primeiramente, se faz necessária uma apreciação dos meios de pagamentos no contexto mundial, com ênfase no Brasil e, em seguida, é feita uma análise com base nos dados existentes sobre o comportamento do consumidor neste ano de vigência de Lei 13.455/17.

\subsection{Os Meios de Pagamentos no Mundo e no Brasil}

A forma de representação e a materialidade da moeda passaram por transformações que permearam a história do desenvolvimento da humanidade. (FARIAS, 2016). O surgimento dos meios de pagamento sobreveio da necessidade de os indivíduos realizarem trocas comerciais (DAVIES, 2002, p. 10). Desde o escambo, forma primitiva de realizar trocas de mercadorias, os meios de pagamento foram se adaptando ao desenvolvimento econômico das civilizações. A moeda surgiu a fim de desempenhar três funções principais: meio de troca, unidade de conta e reserva de valor (FRANK e BERNANKE, 2012, p. 591), uma vez que tais funções permitem a especialização dos indivíduos aumenta a efíciência econômica e o padrão de vida material.

De acordo com Calzon (2005) as economias ocidentais estão sendo transformadas em economias de serviços. A evolução tecnológica mudou a forma de efetuar transações financeiras o que também afetou os meios de pagamento. Segundo Fuzitani (2007), as transações deixaram de ser somente físicas para se apoiar no processamento de dados como seu principal meio, o que conferiu mais flexibilidade e velocidade no pagamento. Atualmente, percebe-se a enorme difusão que os cartões de débito e de crédito alcançaram na economia mundial.

O Brasil possui características únicas no que se refere ao mercado de crédito no cenário mundial. Se, por um lado, apresenta uma das maiores taxas de juros para compras parceladas no crédito rotativo, por outro lado, é prática do comércio oferecer parcelamento em maior número de vezes sem juros, mesmo para itens de baixo custo. (SCIARETTA, 2018).

O sistema bancário brasileiro configura-se na estrutura de mercado denominada oligopólio, ou seja, poucas empresas atuam no mercado. Os indicadores de concorrência calculados para o período de 2000 a 2017 pelo Banco Central do Brasil apontam que houve aumento da concorrência bancária no período. Maior concorrência significa menor custo do crédito (BACEN, 2017).

Entretanto, um estudo realizado pela Proteste em dezembro de 2017 mostra que enquanto no Brasil os juros com crédito rotativo de cartão são de em média 353\% a.a., na Argentina são 47\% 
a.a., no Chile 22\%a.a. e em Portugal 16\%a.a.a. Em razão das taxas muito altas, o rotativo do cartão de crédito, no Brasil ano de 2017, foi mais utilizado por indivíduos de menor renda, menor tempo de emprego, aqueles recentemente desligados do mercado de trabalho formal e beneficiários de programas sociais (BACEN, 2017).

\subsection{Evidências dos impactos da diferenciação de preços para o acesso ao consumo no Brasil}

A partir da hipótese de que consumidores que pagam com cartão de crédito estariam sendo, implicitamente, subsidiados pelos outros consumidores (CHAKRAVORTI E EMMONS, 2003; CHAKRAVORTI E TO: 2007), pretende-se, nessa seção verificar se a autorização legal para a utilização de diferenciação de preços trouxe impactos para a economia brasileira e de que forma.

A comissão de Estudos do Banco Central que elaborou a lei chegou a conclusão de que a parcela da população que não usa cartão de crédito (60\% dos consumidores) estava financiando quem usa (os outros 40\%). E dentre os que usam, os usuários mais pobres (que pagam anuidade do cartão e não usam milhas para viajar) pagavam subsídios para os mais ricos.

Sendo assim a finalidade da lei de diferenciação de preços, de acordo com Henrique Meirelles, é a redução do subsídio cruzado entre consumidores que pagam em dinheiro e no cartão. As compras em cartão envolvem a cobrança de taxas pelas operadoras e que são repassadas aos consumidores. Com a regra que previa preço único para os produtos, tanto aqueles que pagam em dinheiro quanto os que pagam com o cartão acabavam sendo onerados por esse custo extra $(\mathrm{O}$ GLOBO, 2018).

Schmalensee (2002) conclui que a tarifa de intercâmbio desloca os custos entre emissores e credenciadores, e, consequentemente, também afeta a distribuição da tarifação sobre comerciantes e consumidores.

Diante dessas fundamentações teóricas, fez-se um estudo empírico, verificando os dados de saldo de operações de créditos em serviços financeiros, conforme evidenciado abaixo.

Gráfico 1: Saldo de operações de crédito - serviços financeiros 


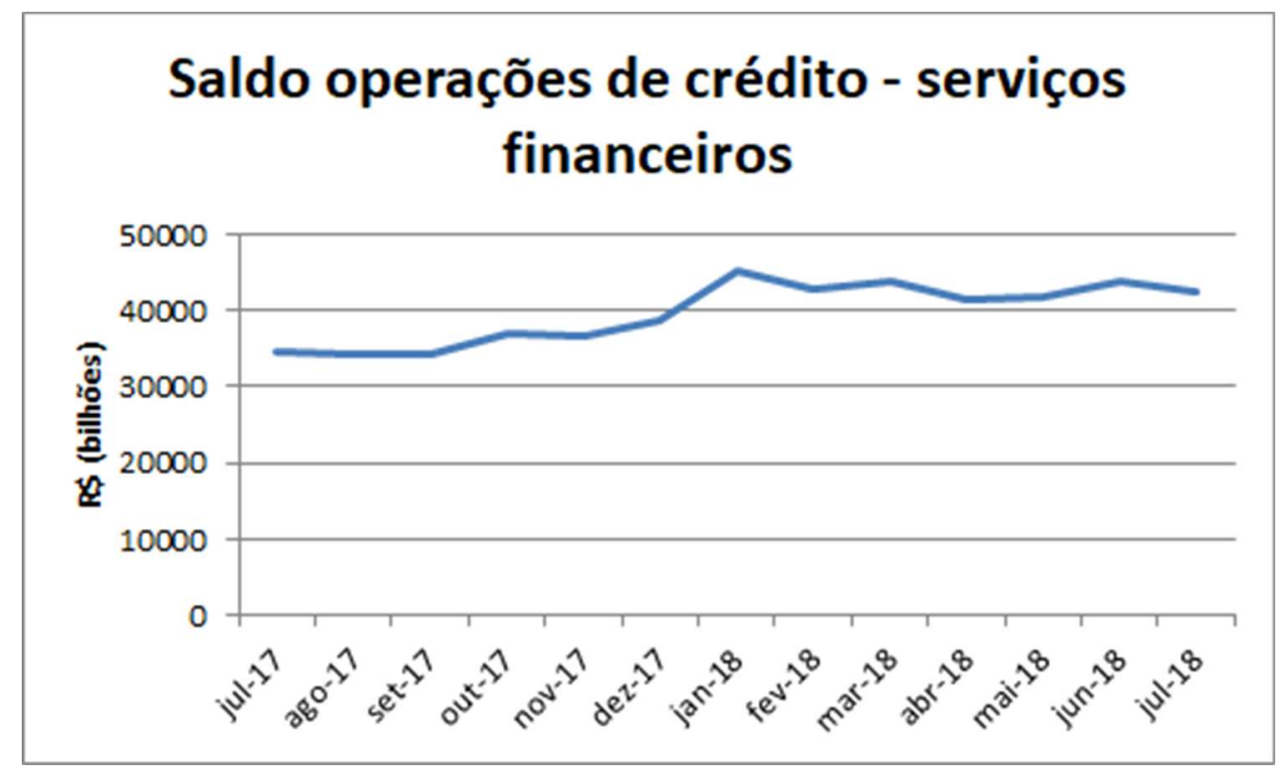

Fonte: Elaboração própria, dados Banco Central do Brasil (2018)

Conforme se verifica no Gráfico 1 acima, o saldo de operações de crédito está em uma tendência de crescimento desde a vigência da Lei 13.455/17 até julho de 2018. Em 2017, o mercado de crédito evoluiu de forma consistente com a recuperação da atividade econômica e os estímulos provenientes do atual ciclo de política monetária e essa trajetória está se mantendo no ano de 2018, parecendo ser pouco relevante os atrativos da diferenciação de preços como um todo.

Os dados apresentados no Gráfico 1 refletem a situação do crédito da economia de maneira agregada, contemplando tanto as pessoas físicas, como jurídicas. A fim de se analisar o impacto ao pequeno consumidor, criaram-se os dois gráficos a seguir, que contemplam dados de consumo no varejo, a partir de dados obtidos no Banco Central do Brasil.

Pela análise do Gráfico 2, é possível observar que nos últimos 12 meses, a utilização de crédito no varejo para bens não duráveis foi volátil. As vendas no varejo para bens não duráveis sofreram impactos sazonais, como o do considerável aumento das vendas em dezembro, em virtude da gratificação natalina recebida pelos consumidores. Verifica-se, porém, que o patamar estabelecido em julho de 2018 está muito próximo ao de julho de 2017, não refletindo significativas variações perceptíveis em relação a nova legislação de diferenciação de preços.

Gráfico 2: Saldo de operações de crédito - varejo- bens não duráveis 




Fonte: Elaboração própria, dados Banco Central do Brasil (2018)

O Gráfico 3, assim como o Gráfico 2 traz o saldo de operações de crédito, porém para bens duráveis. Considerou-se importante avaliar os bens duráveis do varejo, uma vez que diante da necessidade de bens duráveis, é mais comum no Brasil, em que as pessoas não dispõem do valor à vista para sua aquisição, o parcelamento sem juros a crédito. Pela análise dos dados do Gráfico 3 , ficou evidente que as vendas do varejo de bens duráveis também são extremamente afetadas em dezembro, pelo acréscimo de renda dos trabalhadores e pelo apelo comercial das datas festivas.

Cabe salientar, no entanto, que ao contrário dos bens não duráveis, no caso dos bens duráveis, há uma tendência de crescimento nas operações realizadas a crédito para a sua aquisição. Isso demonstra que os consumidores estão mais dispostos a contraírem uma dívida a crédito para obterem bens duráveis e a oferta de possibilidade de parcelamento continua sendo atrativa e utilizada pelos indivíduos, mesmo com a implementação da Lei 13.455/2017.

Gráfico 3: Saldo de operações de crédito - varejo- bens não duráveis 


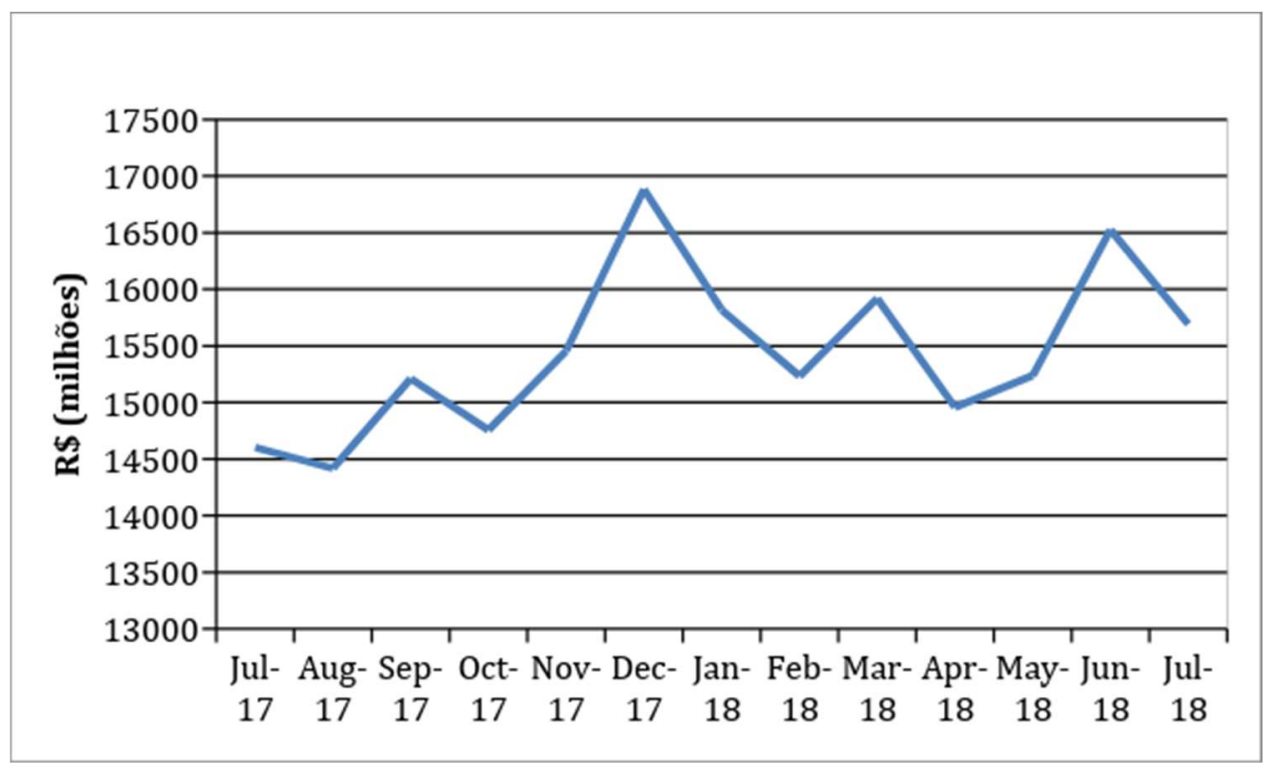

Fonte: Elaboração própria, dados Banco Central do Brasil (2018)

\section{CONCLUSÃO}

A mudança da legislação, primeiramente pela Medida Provisória 764 em 2016 e depois mediante a Lei 13.455/17, trouxe segurança jurídica ao mercado - zerando as demandas judiciais sobre o tema - por tornar pacífica a possibilidade diferenciação de preços tendo em vista os meios de pagamento - dinheiro, cheque, débito e crédito. Para realizar tal mudança legislativa, foi feito um estudo prévio do Banco Central do Brasil sobre os impactos da medida na economia, tendo os resultados estimados numa alteração benéfica, especialmente para os consumidores considerados pertencentes ao grupo vulnerável de baixa renda. No entanto, fica evidenciada a falta de integração entre os diversos agentes estatais, uma vez que os órgãos de defesa do consumidor como a SENACON e os PROCONs estaduais e municipais não foram consultados no processo de elaboração desta lei.

Contudo, a resposta sobre a validade desta medida não é simples. A prática implementada valorização do dinheiro como meio de pagamento - que vem em sentido oposto à tendência mundial que é o fim da circulação do papel-moeda, em virtude do avanço da tecnologia digital, e cujos impactos serão percebidos na economia nos próximos anos. Há uma acirrada disputa entre os bancos e fintechs emissores destes cartões e também entre as credenciadoras (empresas responsáveis pela inclusão dos estabelecimentos comerciais ao sistema de captura e processamento das transações de cartões). A competição das credenciadoras, especificamente, está centrada nos aspectos de precificação dos serviços, nas soluções tecnológicas e na oferta de programas de benefícios aos 
consumidores. Há, ainda, o interesse governamental no registro de todas as transações para fins de arrecadação de impostos, o que por vezes não é feito quando a venda é feita em dinheiro.

Embora não haja dados oficiais sobre os descontos oferecidos ao consumidor pelas vendas realizadas em dinheiro neste curto espaço de vigência da Lei 13.455/17, do ponto de vista teórico, reduzir o custo final dos produtos, ao excluir o custo das operadoras de cartões de crédito, é bom tanto para os comerciantes, quanto para os consumidores. Para os comerciantes, a queda no preço final permite aumento no volume de vendas, especialmente para as pequenas empresas que possuem mais flexibilidade na negociação e estão dispostas, se necessário, a baixar o percentual de lucro. Para o consumidor, especialmente para o grupo mais vulnerável economicamente, a lei coloca fim na prática o subsídio cruzado, em que os mais pobres pagavam o custo do meio de pagamento do mais rico.

Conforme os dados empíricos analisados neste trabalho, percebe-se, todavia, que as vendas com cartões de crédito permanecem subindo durante o período analisado, que contempla o início da vigência da lei (julho de 2017) e os 12 meses subsequentes, ou seja, julho de 2018, demonstrando que as pessoas que têm acesso ao crédito optam por utilizá-lo, por conferirem benefícios como possibilidade de parcelamento, segurança e vantagens indiretas, como participação em programas de milhagens das operadoras de cartões.

Devido a essa nova medida de diferenciação de preços na economia brasileira, ainda é difícil prever uma tendência no mercado, possibilitando tanto o aquecimento da economia, quanto a redução das transações na economia formal e certamente outras incertezas operacionais surgirão, como, por exemplo os critérios de fixação do preço à vista e sua informação para o consumidor, bem como dos benefícios para a utilização de meios de pagamento diferenciados.

Cabe destacar, ainda, que o Banco Central do Brasil implementou uma nova regulamentação de arranjos e instituições de pagamento, para as compras a débito, que passou a vigorar a partir de outubro de 2018, em que a tarifa que hoje não é regulada passará a ter média estabelecida em $0,50 \%$ do valor da transação e a máxima em $0,80 \%$. Tal mudança poderá acarretar em alterações nos preços repassados ao consumidor final nas compras realizadas a débito com o uso de cartão bancário.

Por fim, não há como negar que apesar de todas as nuances que o problema possui, a elaboração da lei foi feita com base em estudos matemáticos, tendo como objetivo o melhor funcionamento do mercado como um todo, mas especialmente para os consumidores vulneráveis do ponto de vista econômico, ou seja, a parcela mais pobre da sociedade brasileira. E, de acordo com as evidências trazidas pelos dados do Banco Central, percebe-se que as classes média e alta não alteraram até o momento a preferência pelo uso do cartão de crédito, aproveitando-se das 
vantagens trazidas pelos parcelamentos sem juros junto ao lojista e pelos programas de milhagens e promoções.

\title{
THE IMPACTS TO THE CONSUMER OF DIFFERENTIAL PRICING IN ACCORDANCE TO THE MEANS OF PAYMENT
}

\begin{abstract}
This paper aims to verify the impact of Law n. 13.455/17, about differential pricing, to the consumer, by employing the Law and Economics methodology. The legal framework of this subject is presented in the first part, when it is compared the previous prevailing understanding that forbids differential pricing with the current legislation that permits it. The second part deals with the economic vulnerability of the consumer considered both as an individual and as a group. Finally, using data from the Central Bank, this work describes the means of payment in Brazil and analyzes the empirical evidence on the credit market in an unprecedented manner.
\end{abstract}

Keywords: Differential pricing. Law and Economics. Consumer Law. Vulnerable groups. Economic vulnerability.

\section{REFERÊNCIAS}

BANCO CENTRAL DO BRASIL. Plano de Ação para Fortalecimento do Ambiente Institucional: relatório 2012-2014 / Parceria Nacional para Inclusão Financeira - Brasília: Banco Central do Brasil, 2014. - Brasília: Banco Central do Brasil, 2014. Disponível em: $<$ https://www.bcb.gov.br/pec/appron/apres/Relat\%F3rio\%20PNIF\%20-\%20Br.\%200462.pdf $>$.

Acesso em 5.set.2018.

BANCO CENTRAL DO BRASIL. Disponível em: $<$ https://www.bcb.gov.br/pec/depep/spread/REB_2017.pdf>. Acesso em 5.set.2018.

BARCELlOS, Daniela Silva Fontoura de. O consumidor em sentido próprio no Brasil e na Argentina. Revista de Direito do Consumidor, v. 63, p. 92-130. Jul.-set./2007.

BOURGOGNIE, Thierry. "O conceito jurídico de consumidor". Revista de Direito do Consumidor, São Paulo, n. 2, p. 7-51. jan.-mar./1992.

CARAN, Bernardo. "Temer sanciona lei que permite preço diferente para cada forma de pagamento". Jornal O Globo, 26/06/2017 Disponível em: <https://g1.globo.com/economia/seudinheiro/noticia/temer-sanciona-lei-que-permite-preco-diferente-para-cada-forma-depagamento.ghtml >. Acesso em: 5.set.2018.

CARLZON, Jan. A Hora da Verdade. Rio de Janeiro: Sextante, 2005. 
CAVALIERI, Sérgio. Programa de Direito do Consumidor. $4^{\mathrm{a}}$ ed. São Paulo: Atlas, 2014.

CAVALLI, Cássio. Empresa, Direito e Economia. Rio de Janeiro: Forense, 2013.

CONGRESSO NACIONAL. Medida Provisória $n^{\circ}$ 764, de 2016. Diferenciação preços.

Disponível em: https://www.congressonacional.leg.br/materias/medidas-provisorias//mpv/127887. Acesso em: 22.ago.2018.

COOTER, Robert e ULEN, Thomas. Direito e Economia. Porto Alegre: BookSeller, 2010.

CHAKRAVORTI, S.; EMMONS, W. (2003). Who pays for credit cards? Journal of Consumer Affairs. Vol. 37, p. 208-230.

CHAKRAVORTI, S.; To, T. (2007). A theory of credit cards. International Journal of Industrial Organization. Vol.25, p. 583-595.

CORRÊA, Marcos . "Sancionada lei que permite preço diferente para compra em dinheiro". Sítio do Ministério da Fazenda. publicado em 26/06/2017, às 16h 40min. Disponível em: $<$ fazenda.gov.br/noticias/2017/junho/sancionada-lei-que-permite-preco-diferente-para-compraem-dinheiro> Acesso em: 4.set.2018.

DAVIES, Glyn. A History of Money From Ancient Times to the Present Day. $3^{\text {a }}$ edição. Cardiff: University of Wales. 2002.

FARIAS, Luciana Mattos. Inovação tecnológica e expansão do acesso aos serviços bancários: a evolução do mercado brasileiro de meios de pagamentos eletrônicos e o dispositivo mobile. Dissertação de Mestrado. UFRGS, 2016.

FRANK, Robert H.; BERNANKE, Ben S. Princípios de Economia. 4. ed. Porto Alegre: AMGH, 2012.

FUZZITANI, Eric Akira. Meio eletrônico de pagamento e desempenho no varejo: estudo comparativo de setores na adoção de um cartão de loja como meio de pagamento. Trabalho de conclusão de curso. Departamento de Administração. Faculdade de Economia, Administração e Contabilidade. Universidade de São Paulo. 2007. Disponível em: $<$ http://www.ead.fea.usp.br/TCC/trabalhos/ArtigoEric\%20Akira.pdf.> Acesso em: 30.out.2017.

GARCIA, Leonardo de Medeiros. Direito do Consumidor: Código Comentado e Jurisprudência. Niterói: Impetus, 2011.

GUERRA, Sidney e EMERIQUE, Lilian Balmant (orgs.). Direito das minorias e grupos vulneráveis. Ijuí: Unijuí, 2008.

MARQUES, Cláudia Lima. Contratos no Código de Defesa do Consumidor: o novo regime das relações contratuais. São Paulo Revista dos Tribunais, 2014.

MARQUES, Cláudia; BENJAMIN, Antonio Herman e MIRAGEM Bruno. Comentários ao Código de Defesa do Consumidor. $8^{\text {a }}$ ed. São Paulo: Revista dos Tribunais, 2016. 
MARQUES, Cláudia Lima e MIRAGEM, Bruno. O novo direito privado e a proteção dos vulneráveis. $2^{\mathrm{a}}$ ed. São Paulo: Revista dos Tribunais, 2016.

MIRAGEM, Bruno. Curso de Direito do Consumidor. $6^{\text {a }}$ ed. São Paulo: Saraiva, 2016

MORAES, Paulo Valério Dal Pai. Código de Defesa do Consumidor: princípio da vulnerabilidade no contrato, na publicidade e nas demais práticas comerciais. Porto Alegre: Livraria do Advogado, 2009.

PROCON-SP. "A diferenciação de preços. Procon-SP se manifesta contrário à MP 764/2016 que permite a diferenciação de preços de acordo com o meio de pagamento" Fundação Procon São Paulo. em 10/2/2017. Disponível em: <www.procon.sp.gov.br/noticia.asp?id=4970> Acesso em: 5.set.2018.

PROTESTE. "brasileiro paga os maiores juros do Mundo. Disponível em: $<$ https://www.proteste.org.br/dinheiro/cartao-de-credito/noticia/brasileiro-paga-os maiores-jurosdo-mundo. $>$. Acesso em: 05.set.2018.

SCIARETTA, Toni. Brasileiro usa cartão e parcela 70\% das compras. Folha de São Paulo. Disponível em: $\quad<$ https://www1.folha.uol.com.br/fsp/mercado/30175-brasileiro-usa-cartao-eparcela-70-das-compras.shtml>. Acesso em: 05.set.2018.

SCHMALENSEE, R. (2002). Payment systems and interchange fees. Journal of Industrial Economics. Vol. 50, p.103-122.

Trabalho recebido em 07 de setembro de 2018

Aceito em 14 de fevereiro de 2019 